\title{
Road Side Drainage System and Disaster Management using Permeable Concrete
}

\author{
Vicky N. Gupta \\ Graduation Student, \\ Department of Civil Engineering \\ Thakur College of Engineering and \\ Technology, Mumbai, Maharashtra, \\ India
}

\author{
Rajeshwari S. Sozhiachetty \\ Graduation Student, \\ Department of Civil Engineering \\ Thakur College of Engineering and \\ Technology, Mumbai, Maharashtra, \\ India
}

\author{
Prableen Kaur Bhumrah \\ Graduation Student, \\ Department of Civil Engineering \\ Thakur College of Engineering and Technology \\ Mumbai, Maharashtra, India
}

\author{
Darshan Mali \\ Asst. Professor, \\ Department of Civil Engineering \\ Thakur College of Engineering and Technology \\ Mumbai, Maharashtra, India
}

\begin{abstract}
Permeable concrete is a relatively a new concept for road pavements, with increase into the problems in rural and urban areas related to the low ground water level and agricultural livestock problems. Permeable concrete has introduced as a road pavement material. Permeable concrete is now being researched and being optimised to be used as a paving material due to its ability to allow water to flow through itself to recharge groundwater level and minimize storm water runoff and store the excessive water for further use. The invention and utilisation of permeable concrete as pavements showcases its applications and engineering properties, including environmental benefits, structural properties, and durability. In any area, cost consideration is the primary factor which must be kept in mind. Permeable concrete pavement is unique and effective means to meet growing environmental demands. By storing storm water and allowing it to percolate into the ground and collect the excessive water. This Smart Management System of storm water technology creates more efficient land use by eliminating the need for retention ponds, swell, and other costly management devices. The prototype showcases the smart management and working of the project and paper. An attempt to experiment the compressive strength of permeable concrete by varying quantity of sand is also made.
\end{abstract}

Keywords - Storm water, excessive water, permeable concrete, pipe system, water utilization.

\section{INTRODUCTION}

With ever increasing demands for natural resources, we are abiding to adopt several measures that maintain environmental sustainability. One of the leading applications in use of permeable concrete, it is basically more permeable than our regular air entrained concrete. It allows percolation of rainwater through it, it minimizes run off from a site thus refilling of ground water table. With increasing stress on structures like green buildings, permeable concrete is a healthy choice for sidewalks, parking lots, pavements. It is a mixture containing water, admixtures, course aggregate and Portland cement. The mixture does not contain presence of slumps. There is an absence of fine aggregate leading to the development of voids through which water will flow. It is a smart development of land to introduce permeable concrete in structures like low volume pavements, noise barriers, swimming pool decks, tennis coats, rural roads pavements etc.
When we talk about preservation of water from precipitation, generally rain water harvesting is what that comes to our mind. It's effective but covers relatively low surface area, using permeable concrete in pavements, reducing runoff of rain water. It is substitute for expensive rain water management techniques, many factors including density, volume, and variation in size of aggregate in general around 80 to $730 \mathrm{Litres} / \mathrm{min} / \mathrm{m}^{3}$ of water is drained through it . The compressive strength varies from 3-18 MPa. Most of the rain water runs off into drains collecting pollutants which lead to pollution of water in nearby reservoir. It generally contains toxic chemical pollutants and further requires treatment before discharging. Use of permeable concrete is effective solution for these problems. Not only the groundwater table is balanced but there is less need for irrigation as nearly vegetation gets sufficient supply of water. Rapid and very large volumes of drains require sufficiently large drainage systems. Metropolitan regions are significantly warmer when compared to their surroundings because of the urban heat island effect. Impermeable surfaces which once were moist becomes dry are its leading cause. Permeable concrete reduces this effect and helps in reducing temperature. As the uses of permeable concrete have versatile implementations, it has high performance and sustainable buildings; it meets LEED requirements ${ }^{[10]}$. To evaluate performance of a structure in relation to environmental aspect, a rating system- "Leadership in Energy and Environmental Design" is developed. Application of permeable concrete helps to gain LEED points. In any area be it urban or rural the water of the rain or storm falls rapidly on the ground giving it very less time to seep the water in and absorb it and so the water which does not get seeped in the ground gets washed away in the drainage which wastes the water. And so to collect that water we can install pipe systems under permeable concrete and collect the water in artificial reservoirs for further usage.

\section{OBJECTIVES}

1. To minimize and eradicate the risk of surface water accumulation and flooding.

2. To reduce and solve the problems with traditional asphalt surface, water drainage system. 
3. Storm water harvesting and storage under permeable concrete.

4. Use of stored water for versatile uses. (Farms, domestic use, small and medium construction site)

5. Drainage of water to avoid the water logging and better optimization of storm water.

6. To demonstrate the working of the permeable concrete with the help of the prototype.

\section{MECHANISM AND WORKING}

In comparison, the ingredients of permeable concrete are quite similar to conventional asphalt concrete leaving behind fine sand, the size distribution of the course aggregate is kept narrow and bitumen. Permeable concrete is a zero-slump, open graded material where cement, course aggregate, mixtures and water are mixed together as a normal concrete. Permeable concrete is also known as "NO-FINES" or "PERVIOUS" or "Thirsty" concrete as it does not contain fine aggregates such as sand. Local rainfall information is important while installing permeable concrete. (+/-) 90 Litres water are used but not too much or you won't have permeable concrete. The important ingredients which can be i.e. "ADMIXTURE" is mainly consist of:

1) Air entrainer

2) Water reducer

3) Evaporation retarded (helps to prolong hydration).

After manufacturing process there is chances to form $15 \%$ - $30 \%$ voids in permeable concrete, which is useful and essential for transferring water through it. Density of permeable concrete is in between $1600-1900 \mathrm{~kg} / \mathrm{m}^{3}$ per unit weight. Actual compressive strength of permeable concrete is 3 - $20 \mathrm{MPa}$ but it can extent to $28 \mathrm{MPa}$ by adding fine aggregates and admixtures. Flexural strength of permeable concrete is up to $1-2.7 \mathrm{MPa}$ which is very high ${ }^{[7]}$. The Prototype demonstrates the proper follow of water in the permeable concrete. The Proto Tank represents the boundary conditions of the land and the soil in it represents the ground and the sand and gravel just above the soil has a pipe network installed in them and which represents the sub base. When water is poured on the concrete the water seeps into the concrete through the voids and goes to the soil but as the soil take only 31.5 litres or 8.33 gallons of water an hour per square feet assuming it to be fine sand the rest water gets stored in the voids of the concrete and as there are pipes with holes in the concrete to behave as a channel to the flow of water and send the water to the artificial reservoir where the water can be stored for further use after sedimentation.

\begin{tabular}{|c|c|c|c|c|}
\hline Soll Separate & $\begin{array}{l}\text { Particle stze } \\
\text { Dlameter } \\
\text { (mm) }\end{array}$ & Permeability & $\begin{array}{c}\text { Permeability } \\
\text { Rate/ } \\
\text { Percolation } \\
\text { Rate } \\
\text { (inches/hour) }\end{array}$ & $\begin{array}{l}\text { Permeability } \\
\text { (galday/ft2 } \\
\text { soll area) }\end{array}$ \\
\hline Clay & Below 0.002 & Very slow & $\begin{array}{l}\text { Less than } \\
0.05\end{array}$ & 0.025 \\
\hline Silt & $0.05-0.002$ & Slow & $0.05-0.2$ & 0.5 \\
\hline $\begin{array}{l}\text { Very fine } \\
\text { sand }\end{array}$ & $0.10-0.05$ & $\begin{array}{l}\text { Moderately } \\
\text { slow }\end{array}$ & $0.2-0.8$ & 50 \\
\hline Fine sand & $0.25-0.10$ & Moderate & $0.8-2.5$ & 100 \\
\hline Medium sand & $0.5-0.25$ & $\begin{array}{c}\text { Moderately } \\
\text { rapid }\end{array}$ & $2.5-5.0$ & 250 \\
\hline Coarse sand & $1.0-0.5$ & Rapid & $5.0-10.0$ & 2500 \\
\hline $\begin{array}{l}\text { Very coarse } \\
\text { sand }\end{array}$ & $2.0-1.0$ & Very rapid & 10.0 and over & $>2500$ \\
\hline
\end{tabular}

Soil Permeablity Rates

Source: http://slideplayer.com/slide/7904295/

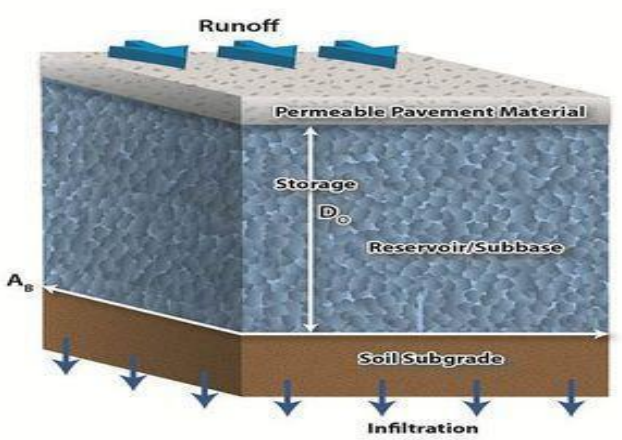

Fig. 1. Percolation Process of Permeable Concrete Source: stormwater.pca.state.mn.us

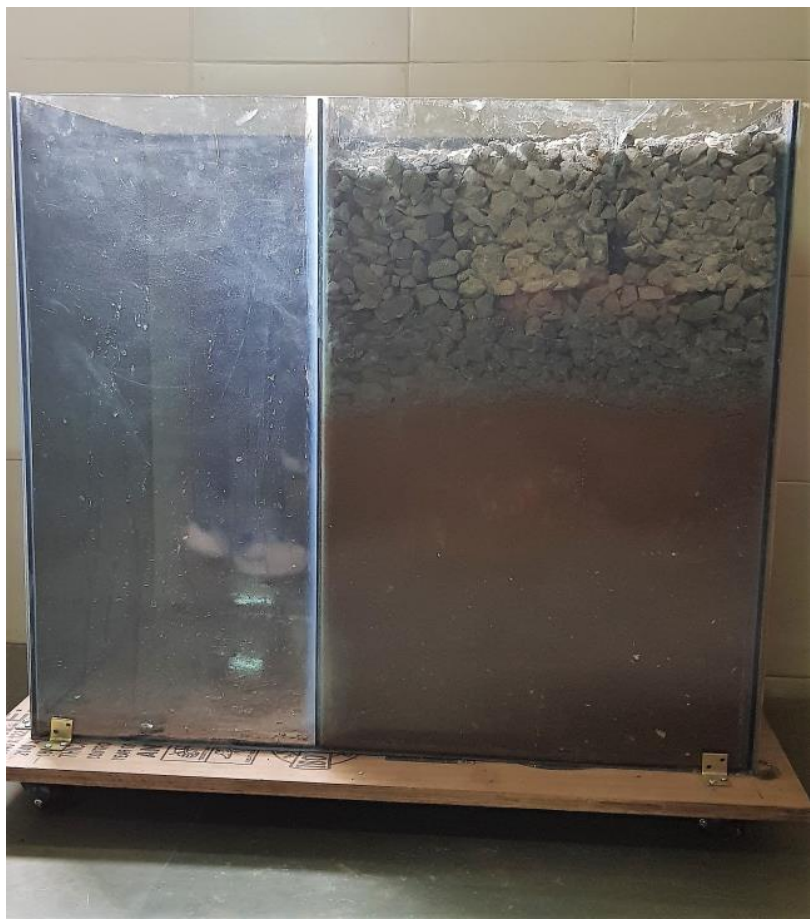

Fig. 2. Demonstrative Prototype of Smart System of Permeable Concrete. 


\section{EXPERIMENTAL APPARATUS}

Ordinary Portland Cement (C 53 grade) conforming to the requirements of IS 12269 (ASTM C 150-85A) was used in the study. Natural river sand was used as fine aggregate and crushed angular stone was used as coarse aggregate. Coarse aggregate of grade $100 \%$ passing through $20 \mathrm{~mm}$ sieve and retained on $10 \mathrm{~mm}$ sieve conforming to IRC 44 was adopted.

\subsection{Mix Proportioning}

An experimental programme was chosen with M20 having cement contents $300-450 \mathrm{~kg} / \mathrm{m}^{3}$ being the practical range considered for normal concrete and that of water is fixed between 90 to 130 litres $/ \mathrm{m}^{3}$ based on the field information published in the literature ${ }^{[6]}$. The water/cement ratio ranges from 0.21 to 0.43 .

\subsection{Method of Mixing and Compaction}

Mixing was done using a pan mixer. Initially the dry mix constituents of the mix namely cement, fine aggregate and coarse aggregate was mixed for two minutes and then the water. The total mixing time was kept at 4 minutes for all the trials until a homogeneous mixture was obtained.

\subsection{Specimens}

Cubes of size $150 \mathrm{~mm}$ were cast and tested for compressive strength at the age of 7, 14 and 28 days and beams of size $150 \times 150 \times 170 \mathrm{~mm}$ at 28 days for flexural strength as per IS 516. All the specimens were kept immersed in water until the time of testing.

\subsection{Preparation of Concrete}

Production of quality concrete requires meticulous care exercised at every stage of manufacture of concrete. Therefore it is necessary to know the good rules to follow in each stage of manufacture of concrete for producing good quality concrete ${ }^{[5]}$

\subsection{Water Curing}

This is by far the test method of curing as it satisfies all the requirement of curing namely promotion of hydration, elimination of shrinkage and adsorption of the heat of hydration.

\subsection{Preparation of Specimens For Testing}

The specimens were taken out from the curing tank on the testing day to prepare them for testing surface water and grit taken wiped off to and allowed to dry for about one hour. The specimens were marked accordingly to their respective mixes ${ }^{[3,5]}$.

\section{CONSTRUCTION}

The Demonstrative Prototype is built to represent the working of the permeable concrete and it can be used for further education purposes. The cost of construction of the prototype was approximately Rs.2,000/-.The Prototype includes the major parts as:

- Glass Tank

- Soil.

- Permeable Concrete Blocks.

- Aggregates

\section{- $\quad$ Pipes.}

\subsection{Glass Tank}

The cost of Glass Tank was Rs. 1.500/- having dimension as 18 inches $\mathrm{x} 20$ inches $\mathrm{x} 30$ inches with having a partition at 17 inches and a hole of 1 inch diameter.

\subsection{Soil}

The approximate weight of soil put in the tank is 40 $\mathrm{kg}$ and it is the soil passed from the $10 \mathrm{~mm}$ sieve. The soil while pouring in the tank was properly tamped and vibrated so as no air is present in between the soil as to represent the normal ground condition.

\subsection{Permeable Concrete Blocks}

The concrete blocks were prepared according the normal procedure.

\subsection{Aggregates}

The fine aggregate is poured above the soil in a thickness of $1 \mathrm{~cm}$ and above that there coarse aggregate so as to represent the sub grade as on the roads.

\subsection{Pipes}

The pipes were placed just above the subgrade so as the water which gets accumulated above the sub grade does not fill up and flow above the concrete and so the water flows in the artificial tanks through these pipes. The upper half of the pipes are holed with diameters of approx. $1 \mathrm{~cm}$.

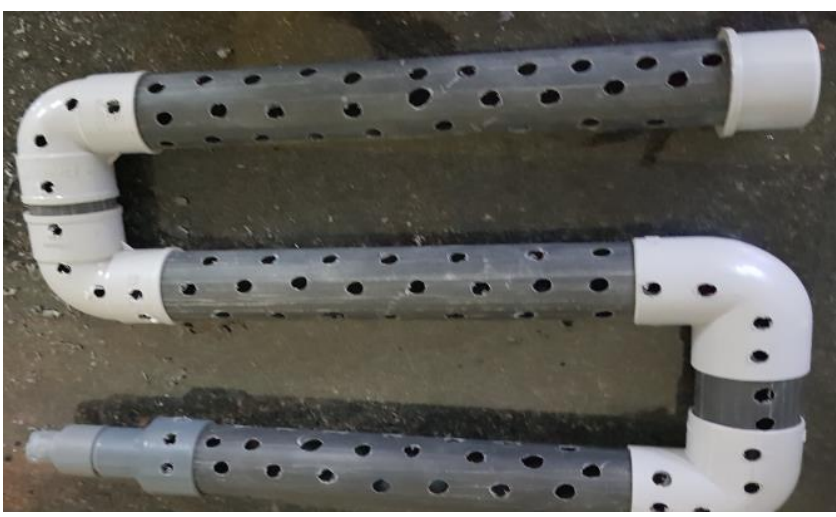

Fig. 3. Pipe system holed and connected having one outlet.

After the assembly of the prototype, it was tested and the prototype worked as the water did not overflow the concrete and was getting collected in the artificial reservoir. 


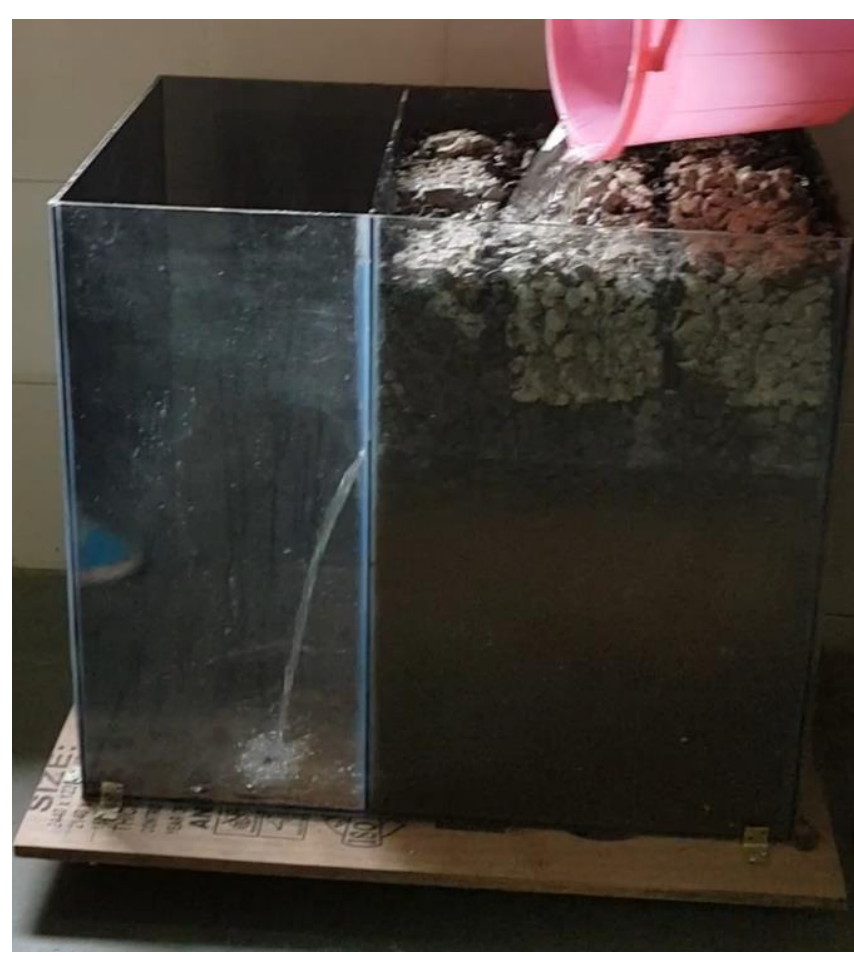

Fig. 4. Testing and Working of the Prototype.

\section{VI.RESULT AND DISCUSSION}

The compressive strength test was done and the blocks were prepared by adding sand and so were tested for compressive strength. The blocks were prepared by adding sand equivalent to the weight of coarse aggregate. Sample M1, M2 and M3 had $0 \%, 10 \%$ and $20 \%$ of sand by weight of coarse aggregate.

\subsection{Compressive Strength Test}

Table 1. Compressive Strength of Permeable Concrete at 7 Days.

\begin{tabular}{|c|c|c|c|}
\hline MIXES & $\begin{array}{c}\mathrm{M} 1 \\
\left(\mathrm{~N} / \mathrm{mm}^{2}\right)\end{array}$ & $\begin{array}{c}\mathrm{M} 2 \\
\left(\mathrm{~N} / \mathrm{mm}^{2}\right)\end{array}$ & $\begin{array}{c}\mathrm{M} 3 \\
\left(\mathrm{~N} / \mathrm{mm}^{2}\right)\end{array}$ \\
\hline Trial 1 & 7.10 & 8.00 & 11.80 \\
\hline Trial 2 & 7.10 & 8.40 & 12.00 \\
\hline Trial 3 & 8.00 & 8.20 & 12.13 \\
\hline Average Strength & 7.40 & 8.20 & 12.64 \\
\hline
\end{tabular}

Table 2. Compressive Strength of Permeable Concrete at 14 Days.

\begin{tabular}{|c|c|c|c|}
\hline MIXES & $\begin{array}{c}\mathrm{M} 1 \\
\left(\mathrm{~N} / \mathrm{mm}^{2}\right)\end{array}$ & $\begin{array}{c}\mathrm{M} 2 \\
\left(\mathrm{~N} / \mathrm{mm}^{2}\right)\end{array}$ & $\begin{array}{c}\mathrm{M} 3 \\
\left(\mathrm{~N} / \mathrm{mm}^{2}\right)\end{array}$ \\
\hline Trial 1 & 8.40 & 10.20 & 12.80 \\
\hline Trial 2 & 8.90 & 9.20 & 14.50 \\
\hline Trial 3 & 8.80 & 9.70 & 13.10 \\
\hline Average Strength & 8.70 & 9.70 & 13.46 \\
\hline
\end{tabular}

Table 3. Compressive Strength of Permeable Concrete at 28 Days.

\begin{tabular}{|c|c|c|c|}
\hline MIXES & $\begin{array}{c}\text { M1 } \\
\left(\mathrm{N} / \mathrm{mm}^{2}\right)\end{array}$ & $\begin{array}{c}\mathrm{M} 2 \\
\left(\mathrm{~N} / \mathrm{mm}^{2}\right)\end{array}$ & $\begin{array}{c}\mathrm{M} 3 \\
\left(\mathrm{~N} / \mathrm{mm}^{2}\right)\end{array}$ \\
\hline Trial 1 & 8.60 & 11.20 & 13.80 \\
\hline Trial 2 & 9.05 & 9.80 & 16.50 \\
\hline Trial 3 & 8.90 & 10.70 & 13.70 \\
\hline Average Strength & $8 . .85$ & 10.56 & 14.67 \\
\hline
\end{tabular}

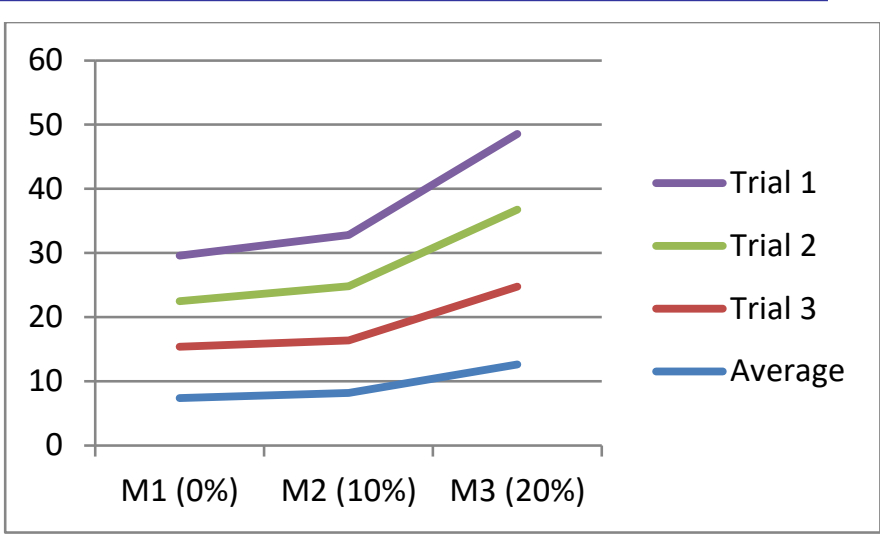

Graph 1. Compressive Strength of Permeable Concrete at 7 Days.

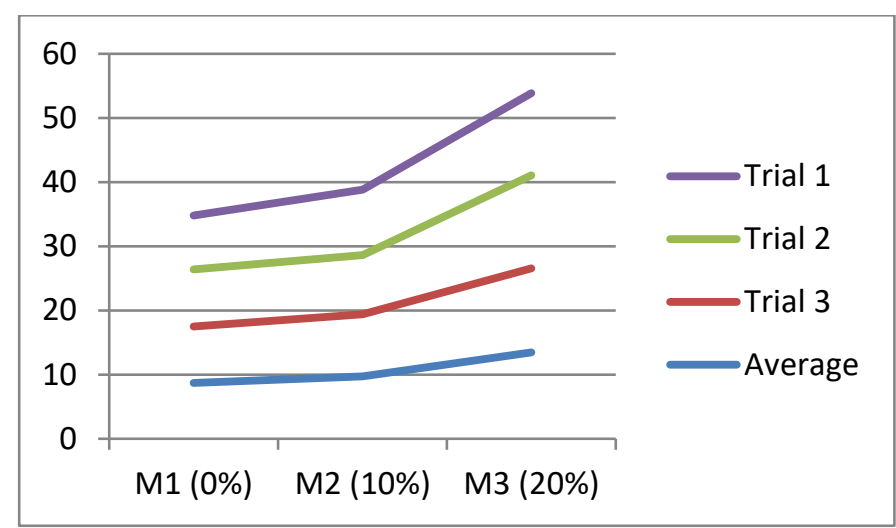

Graph 1. Compressive Strength of Permeable Concrete at 14 Days.

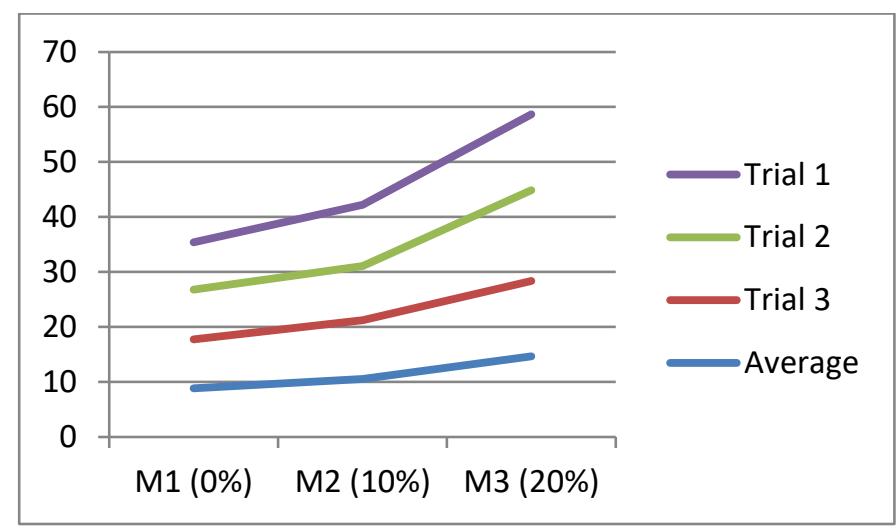

Graph 1. Compressive Strength of Permeable Concrete at 28 Days.

From the above results, we came to know that, the mix M3 with $20 \%$ fine aggregate yields good compressive strength and flexural strength. The permeability rate is higher for mix M1 with $0 \%$ fine aggregate. The mix M2 with $10 \%$ fine aggregate yields good compressive strength.

\section{BASIC INSTALLATION RECOMMENDATIONS FOR PERMEABLE PAVEMENT}

- Zero slump must be maintained as it is good.

- Usage of vibratory truss or rollers to spread the concrete.

- Compact materials with rollers.

- No need for trowelling. 
- Cure using plastic sheeting.

- $\quad$ Curing period $=7$ days

\section{ADVANTAGES OF PERMEABLE CONCRETE}

- Recharge of ground water and local aquifer.

- Water level maintenance and pollution eradication.

- Lessor no need for storm sewer and their maintenance.

- Green building alternative suitable for many application.

- The Natural run-off of water allows rainwater to drain directly to sub-base and seep into ground or get accumulated in the artificial tank.

- Reduced construction cost and requirements for drainage structures.

- Reduced pollution and prevents environmental damage like floods.

- Protects the streams and lakes and allows the local vegetation to thrive.

\section{CONCLUSION}

As there is no use of fine aggregates in permeable concrete, so the cost of permeable concrete is less as compared to conventional concrete ( $25-30 \%$ less). For strength purpose in permeable concrete we can add $20 \%$ of sand as it increases the strength of the concrete. As compared to conventional concrete water drains out quickly in permeable concrete and avoid water logging problem which we face during heavy rainfall especially in metro Politian cites. As compared to conventional concrete the surface of permeable concrete is less smooth but to get more smoothness we can use paving blocks on the surface of permeable concrete. The water accumulated can be used for gardening and so the rain water will seep in the ground and add to ground water in one or the other way. The municipal water saved by using the collected water can save thousands of litres of drinking water.

\section{REFERENCES}

[1] http://www.Clemson.Edu/Extension/Hgic/Water/Resources_Stormwate r/Introduction_To_Porous_Pavement.Html.

[2] https://Stormwater.Pca.State.Mn.Us/Index.Php/Calculating_Credits_Fo r_Permeable_Pavement

[3] International Journal Of Engineering Trends And Technology (IJETT) - Vol.4 Issue.8 - August 2013 ISSN: 2231-5381- Page 3495 PERMEABLE Concrete: New Era For Rural Road Pavement.

[4] S.O. Ajamu, A.A. Jimoh and J.R. Oluremi, "Evaluation Of Structural Performance Of PERMEABLE Concrete In Construction" International Journal of Engineering and Technology Volume 2 No. 5, May, 2012

[5] Tayabji, Shiraz Van Dam, Tom Smith, Kurt, "The Advanced Concrete Pavement Technology (ACPT)", 2009/3,https://trid.trb.org/view/904104

[6] "Report on PERMEABLE Concrete". American Concrete Institute 2010. ISBN-9780870313646. Report No. 522R-10.

[7] "PERMEABLE Ready Mix Concrete". srmconcrete.com. Retrieved 19 November 2015.

[8] "Compressive Strength of PERMEABLE Concrete Pavements". Florida Department of Transportation. Retrieved 1 October 2012.

[9] "Storm Water Technology Fact Sheet: Porous Pavement. United States Environmental Protection Agency, EPA 832-F-99-023, September 1999.

[10] "Using PERMEABLE Concrete to Achieve LEED Points". National Ready Mixed Concrete Association. Retrieved 1 October 2012.

[11] "Filtration of Polluted Waters by PERMEABLE Concrete". Liquid Asset Development. Retrieved 3 October 2012. 